\title{
Validation the Measures of Self-Directed Learning: Evidence from Confirmatory Factor Analysis and Multidimensional Item Response Analysis
}

\section{Chaiwichit Chianchana}

\author{
Faculty of Technical Education, King Mongkut's University of Technology North Bangkok, Thailand \\ Email: chianchana@gmail.com
}

\section{Doi:10.5901/mjss.2015.v6n4p579}

\begin{abstract}
This research aims to validate the measures Self-Directed Learning (SDL) model for technical college students by using confirmatory factor analysis and multidimensional item response analysis. The model was developed based on the theories by Guglielmino (1977), Rogers (1983) and Cross (1981). The sample for the study included 1, 563 students from technical colleges affiliated with the Office of the Vocational Education Commission of Thailand. The instrument employed for the study was four-option situation evaluation. Data were analyzed through the methods of means, standard deviation, confirmatory factor analysis, and multidimensional item response analysis. The results were: 1) Confirmatory factor analysis: items were suitable for the SDL mode(factor loading ranged from .00 and .63) I. 2) Multidimensional item response analysis: items were suitable for the SDL model as well(the OUTFIT MNSQ ranged from .95 to 1.05, and the INFIT MNSQ ranged from .96 to 1.05). The study concludes that the measures of SDL model employed for technical college students of Thailand were valid.
\end{abstract}

Keywords: self-directed learning ,validation ,confirmatory factor analysis, multidimensional item response analysis

\section{Introduction}

Education is key to human resource development and the foundation of the country's growth. Education has to adjust to the changes in the scientific, technological, social, economic and cultural domains. Self-Drected Learning (SDL) is a characteristic essential for learners in the modern world where everything changes so rapidly. It has become one of the primary aims of education in the last few decades. According to Williamson (2007) self-direction is the basis of all type of learning. This is consistent with the Thailand's National Education Act, Section 1 (General: Objectives and Principles, Article 7), stating that the learning process must encourage learners to continuously rely on themselves, be creative, eager for knowledge and learn independently (Office of the Education Council, 2002).

$\mathrm{SDL}$ is a permanent approach which can take place in any situation and allows the individuals to determine their own learning goals and personal approach (Abdollahi, 2009). SDL is also a method of instruction that can be defined in terms of the amount of responsibility the learner accepts for his or her own learning (Fisher et al., 2001) According, a learner who practices SDL initiates challenging activities and develop personal knowledge and skills to pursue these challenges successfully (Gibbons, 2002). So, it is a trait important for education and everyday life.

SDL can be viewed as a process or as a psychological aspect, mainly as an attribute of personality. A high score from using the scale. Since the development of the scale, several studies have supported its reliability and validity (Guglielmino, 1989; Guglielmino \& Guglielmino, 2003) although other researchers have raised issues concerning the construct validity of the instrument (Field, 1991; Hoban, Lawson, Mazmanian, Best, \& Seibei, 2005). The SDLscale for technical college students affiliated with the Office of Vocational Education Commission of Thailand was initially developed as an alternative to Guglielmino's (1978) approach integrating the three different concepts from Guglielmino, Rogers and Cross. Since the development of the Guglielmino SDL scale, there has been significant scrutiny of its underlying theoretical constructs and factor structure. Failure in repeated attempts to replicate the eight-factor structure of the scale proposed by Guglielmino (1977) has raised concerns of its construct validity (Field, 1989, 1991; Hoban et al., 2005). Therefore, a valid SDLmodel became an area to be explored more.

\section{Objective of Research}

This research aimed to validate the SDLmodel for technical college students by using the confirmatory factor analysis and multidimensional item response analysis. 


\section{Method}

\subsection{Sample}

The sample of the present study was technical college students affiliated with the Office of Vocational Education Commission of Thailand acquired from two-stage random sampling. The first step was simple random sampling, by which students were classified by region. The provinces with technical colleges were random units. The second step was simple random sampling of students in technical colleges acquired from the first step. Then 1,563 students were sampling units. The number of sample groups were enough according to the principles of analysis of Hair et al. (2006), who suggested determining the size of the sample groups using the ratio of the number of variables to the number of samples, 1:20. This research had eight variables. Therefore, there should be 160 sample units according to the principles of analysis set out in the multidimensional Rasch model. There were 200 students in the sample group (Wright \& Stone, 1979 cited in Yen \& Fitzpatrick, 2006).

\subsection{Instrument}

The initial instrument had 44 items with four choices developed from two principles: the factor principle and the SDLprinciple. The latter was developed from the work of Guglielmino (1977), which was adapted to suit the Thai context. This principle includes eight factors: 1) openness to learning opportunities, 2) self-conception as an effective learner, 3) initiative and independence in learning, 4) informed acceptance of responsibility for one's own learning, 5) love of learning, 6) creativity, 7) a positive orientation to the future, and 8) the ability to use basic study skills and problem-solving skills. The SDLprinciple was synthesised from Rogers's concept of new knowledge introduction (Rogers, 1983) and Cross's concept of SDL(cross, 1981): Awareness (1 score), interest (2 scores), attempts at learning (3 scores) and practice (4 scores).

The evidence of reliability and validity of the multi-method used in this model was tested for internal consistency and stability, while the construct validity was tested by correlation analysis, and comparative analysis. The sample group for this study was 119 technical college students. This first re-test found a reliability, in terms of internal consistency of .67 , the second re-test scored .74 and stability was calculated at .60. The construct validity of the test was related to a medium-to-high level and the SDL model did not change with time. The final instrument for this research was selected 32 items by item total correlation from 230 technical college students (Cronbach's alpha coefficient $=.67$ ).

\subsection{Procedure}

The research procedure was as follows. First, relevant documents were collected. Additional studies on SDL were conducted. Secondly, research instrument was developed according to factors and the learning sequence. Third, the instrument items were selected. Fourth, validation of the model by confirmatory analysis based on the Classical Test Theory (CTT) was conducted using the LISREL and multidimensional item response analysis based on the Item Response Theory (IRT) wich was conducted using the Conquest 2.0.

\section{Results}

\subsection{Examination of Dimension}

The sample group for study in dimension was 230 technical college students. the scale was tested for its unidimensionality and multidimensionality. Reckase (1979) states that a first factor's variance of at least $20 \%$ of all variances can indicate the unidimensionality of a scale. A scale's unidimensionality can also be measured by looking at the ratio between the eigenvalue of a first factor and that of a second factor, with a value of 3.00 or more indicating unidimensionality (Morizot, Ainsworth \& Reise, 2007). The eigenvalue of the first factor was 3.166, with a variance of $9.893 \%$ of all variances. The percentage of the variance was lower than the value indicating unidimensionality, as suggested by Reckase. In addition, the ratio between the first factor's eigenvalue and the second factor's eigenvalue was found at 1.710, which was lower than the value indicating unidimensionality, as suggested by Morizot, Ainsworth and Reise. The results from the aforementioned measurements indicate that the present research's SDLscale can be employed as a multidimensional scale. (Table 1.) 
Table 1: Eigen values, percentage of variance, and Eigen value F1 / Eigen value F2 of self- directed learning

\begin{tabular}{ccc} 
& $(\mathrm{n}=230)$ \\
\hline$(\mathrm{F})$ Factors & Eigen values & \% of Variance \\
\hline 1 & 3.166 & 9.893 \\
2 & 1.852 & 5.789 \\
3 & 1.583 & 4.947 \\
\hline \multicolumn{3}{c}{}
\end{tabular}

\subsection{General Information of Respondents for Evidence Validity}

The respondents were technical college students: 428 from the North (27.45\%), 380 from the Central Region (including the East) (24.31\%), 379 from the Northeast, $(24.25 \%)$ and 375 from the South (23.99\%). The proportion of males and females was 1,157 males (74.02\%) to 386 females (24.70\%), with 20 not indicating their gender (1.28\%). Regarding education, more than half of the students were pursuing vocational diplomas - 879 students (56.24\%) and 684 students (43.76\%) were pursuing high vocational certificates. Their collective GPA was 2.84 (s=.48).

Analysis of the basic statistics concerning SDL showed the means to be between 2.39 and 3.08. Standard deviation was 1.00 to 1.19. Most responses were negative skewness and platykurtic. The correlation coefficients were from -.004 to .185. The measure of sampling adequacy (MSA) was between .50 and .79. Overall items yielded predictions without discrepancy from the other (100\%), considered from the value of .50 and up (Hair et al, 2006; 2010). The result from Bartlett's Test of Sphericity was 1773.746 ( $d f=496, p=.000)$. This meant that the independent variables in the data analysis were related enough for an analysis of factors and multidimensions. The Kaiser-Meyer-Olkin (KMO) considered .697 to evaluate appropriateness of the data , which was more than that of Hair et al (2006), who suggested upwards of .50. It can therefore be said that the data were appropriate for analysis of factors and multidimensions.

\subsection{Analysis of the SDLModel with Confirmatory Factor Analysis}

In the model structure, factor loading was found to be between .00 and .63. Factor loading of 30 of the items had statistical significance of .05. This showed that most items were significant or related to the factors when other variables were removed. The squared multiple correlations $\left(R^{2}\right)$ of the items were between .00 and .40 . This showed that variation of the items in each factor that could be explained by factors that were at the low to high level: $0.00-40.00 \%$. When the SDL structure and experimental data were examined, the Chi-square test statistics was found to be 418.96 ( $d f=376$, $\mathrm{p}=.062$ ) with no statistical significance. The goodness-of-fit index (GFI) was .98, and the adjusted goodness-of-fit index (AGFI) was .98. The root mean squared residual (RMR) was .023, while the root mean squared error of approximation (RMSEA) was .008. The Index of the model showed congruence between the SDLmodel and empirical data, i.e. the SDLmodel of technical college students had construct validity. (Table 2).

Table 2: Analysis of the SDLModel with Confirmatory Factor Analysis

\begin{tabular}{|c|c|c|c|c|c|}
\hline Factor & item & $b$ & SE & $\mathrm{t}$ & $\mathrm{R}^{2}$ \\
\hline \multirow[t]{4}{*}{ OLO } & 01 & .04 & .04 & 1.12 & .00 \\
\hline & $\mathrm{O} 2$ & $.19 *$ & .04 & 5.04 & .04 \\
\hline & 03 & $.45^{\star}$ & .07 & 6.57 & .21 \\
\hline & 04 & $.07^{*}$ & .04 & 1.98 & .01 \\
\hline \multirow[t]{4}{*}{ SEC } & S1 & $.63^{\star}$ & .15 & 4.20 & .40 \\
\hline & S2 & $.12^{\star}$ & .04 & 3.30 & .02 \\
\hline & S3 & .00 & .06 & .07 & .00 \\
\hline & S4 & $.16^{\star}$ & .07 & 2.32 & .03 \\
\hline \multirow[t]{4}{*}{ IIL } & II & $.15^{\star}$ & .03 & 4.43 & .02 \\
\hline & 12 & $.22^{*}$ & .04 & 5.06 & .05 \\
\hline & 13 & $.15^{\star}$ & .03 & 4.56 & .02 \\
\hline & 14 & $.17^{*}$ & .04 & 4.60 & .03 \\
\hline \multirow[t]{4}{*}{ REL } & R1 & $.27^{*}$ & .03 & 7.84 & .07 \\
\hline & R2 & $.35^{\star}$ & .03 & 10.25 & .12 \\
\hline & R3 & $.47^{*}$ & .04 & 12.65 & .22 \\
\hline & R4 & $.15^{\star}$ & .03 & 4.46 & .02 \\
\hline
\end{tabular}




\begin{tabular}{|c|c|c|c|c|c|}
\hline Factor & item & $\mathrm{b}$ & SE & $t$ & $R^{2}$ \\
\hline \multirow[t]{4}{*}{ LOL } & L1 & $.37^{\star}$ & .07 & 5.26 & .14 \\
\hline & L2 & $.26^{*}$ & .05 & 4.81 & .07 \\
\hline & L3 & $.09^{*}$ & .04 & 2.06 & .01 \\
\hline & L4 & $.20 *$ & .08 & 2.64 & .04 \\
\hline \multirow[t]{4}{*}{ CRE } & C1 & $.19^{\star}$ & .05 & 3.47 & .04 \\
\hline & $\mathrm{C} 2$ & $.07^{*}$ & .03 & 2.21 & .01 \\
\hline & C3 & $.07^{*}$ & .03 & 1.99 & .00 \\
\hline & $\mathrm{C} 4$ & $.21^{*}$ & .06 & 3.53 & .04 \\
\hline \multirow[t]{4}{*}{ POO } & P1 & $.17^{\star}$ & .03 & 4.85 & .03 \\
\hline & P2 & $.21^{*}$ & .04 & 5.82 & .05 \\
\hline & P3 & $.27^{\star}$ & .04 & 6.61 & .07 \\
\hline & P4 & $.21^{*}$ & .04 & 5.57 & .04 \\
\hline \multirow[t]{4}{*}{$A B S$} & A1 & $.22^{\star}$ & .04 & 6.20 & .05 \\
\hline & $\mathrm{A} 2$ & $.05^{\star}$ & .04 & 1.55 & .00 \\
\hline & A3 & $.46^{*}$ & .00 & 11.45 & .21 \\
\hline & $\mathrm{A} 4$ & $.39 *$ & .04 & 10.40 & .15 \\
\hline
\end{tabular}

Note. OLO=Openness to Learning Opportunities,SEC=Self Concept as an Effective Learner,IIL=Initiative and Independence in Learning, REL=Informed Acceptance of Responsibility for one' $s$ own Learning, $L O L=L o v e$ of Learning, CRE=Creative, POO=Positive Orientation to the Future,ABS=Ability to use Basic Study Skills and Problem-Solving Skills

\subsection{Analysis of the SDLModel with Multidimensional Item Response Analysis}

The SDL scale was then analyzed for construct validity through a multidimensional item response analysis. The nested models of a multidimensional approach and the composite approach to the SDL scale were analyzed. The deviance statistics $\left(G^{2}\right)$ of the two models were compared by using the likelihood ratio Chi-square statistics-relatively similar to the Chi-square test $(\chi 2)$-as well as degree of freedom, which indicates the difference between the parameter values of the two models (McCullagh \& Nelder, 1990 cited in Wolfe \& Smith, 2007; Allen \& Wilson, 2006; Liu, Wilson \& Paek, 2008). The non-nested models of a multidimensional approach and the consecutive approach were also analyzed by using the Akaike Information Criterion (AIC), in which AIC $=(-2) \log$ maximum likelihood +2 number of parameters) (Akaike, 1987), i.e. $A I C=G^{2}+2 d f$, when $d f$ is the number of parameters (Yao \& Schwarz, 2006). The analyses were performed on the basis of the multidimensional random coefficients, multinomial logit model (MRCMLM; Adams, Wilson \& Wang, 1997), and the analyses of multidimensional form of the partial credit model were performed in the computer program ConQuest 2.0 .

Table 3 shows the comparisons between the scale's multidimensionality and unidimensionality for construct validity. After the multidimensional approach and the composite approach to unidimensionality were compared, the deviance statistic of the multidimensional approach, consisting of cognitive, affective, and skill strategies, was 135,238.762 (132 parameters), while the deviance statistic of the composite approach was 135,273.924 (97 parameters). The deviance statistic of the multidimensional approach was significantly lower than that of the composite approach. In addition, the multidimensional approach and the consecutive approach to unidimensionality were compared, and it was found that the Akaike Information Criterion (AIC) of the multidimensional approach was lower than that of the consecutive approach. For this reason, it can be concluded that the multidimensional SDLmodel (multidimensional approach) was a fitting model than of the unidimensional SDLmodel (the composite and consecutive approaches), thus demonstrating the appropriateness of multidimensionality for measuring SDL and its validity.

Table 3: The comparison between the unidimensionality and multidimensionality of SDL

\begin{tabular}{lccc}
\hline Self directed learning models & $\left(\mathrm{G}^{2}\right)$ Deviance statistics & Number of parameters & AIC \\
\hline Composite approach to unidimensionality & $135,273.924$ & 97 & $135,467.924$ \\
Consecutive approach to unidimensionality & $135,749.423$ & 104 & $135,957.423$ \\
Multidimensional approach & $135,238.762$ & 132 & $135,502.762$ \\
\hline compared with composite approach Multidimensional approach & & \\
$: \chi^{2}=35.162, \mathrm{df}=35\left(\mathrm{G}^{2}\right)$ Likelihood ratio chi-squared statistics & \\
compared with consecutive approach Multidimensional approach & & \\
$135,502.762<135,957.423:($ AIC)Akaike Information Criterion & & \\
\hline
\end{tabular}


The results of the item-fit analysis for the multidimensional SDL model and the items can be seen in Table 4 . The OUTFIT MNSQ values for each of the 32 items ranged from .95 to 1.05, and the INFIT MNSQ values from .96 to 1.05. Since the accepted OUTFIT MNSQ and INFIT MNSQ rating scale was from .600 to 1.400 (Wright et al, 1994), it can be concluded that the multidimensional SDL model was appropriate for each item. The analysis results were shown in the Wright Maps for the multidimensional SDLin Figure 1.

Table 4: The results of the item-fit analysis for the multidimensional SDLmodel

\begin{tabular}{|c|c|c|c|c|c|}
\hline \multirow[t]{3}{*}{ Factor } & \multirow{3}{*}{ items } & \multicolumn{4}{|c|}{ Item fit } \\
\hline & & \multicolumn{2}{|c|}{ (unweighted) OUTFIT } & \multicolumn{2}{|c|}{ (weighted)INFIT } \\
\hline & & MNSQ & $\mathrm{T}$ & MNSQ & $\mathrm{T}$ \\
\hline \multirow[t]{4}{*}{ OLO } & 01 & 1.02 & 0.7 & 1.02 & 0.7 \\
\hline & $\mathrm{O} 2$ & 0.99 & -0.4 & 0.99 & -0.3 \\
\hline & $\mathrm{O3}$ & 0.98 & -0.5 & 0.98 & -0.6 \\
\hline & 04 & 1.01 & 0.3 & 1.01 & 0.4 \\
\hline \multirow[t]{4}{*}{ SEC } & S1 & 0.99 & -0.4 & 0.99 & -0.6 \\
\hline & $\mathrm{S} 2$ & 0.98 & -0.4 & 0.99 & -0.6 \\
\hline & S3 & 1.04 & 1.2 & 1.04 & 1.7 \\
\hline & S4 & 1.01 & 0.2 & 1.01 & 0.4 \\
\hline \multirow[t]{4}{*}{ IIL } & 11 & 1.02 & 0.4 & 1.01 & 0.5 \\
\hline & 12 & 1.00 & 0.1 & 1.00 & 0.1 \\
\hline & 13 & 1.03 & 0.7 & 1.02 & 0.9 \\
\hline & 14 & 1.01 & 0.3 & 1.01 & 0.3 \\
\hline \multirow[t]{4}{*}{ REL } & R1 & 1.00 & 0.1 & 1.01 & 0.4 \\
\hline & $\mathrm{R} 2$ & 0.99 & -0.3 & 0.99 & -0.6 \\
\hline & R3 & 0.95 & -1.3 & 0.96 & -1.5 \\
\hline & R4 & 1.05 & 1.3 & 1.04 & 1.6 \\
\hline \multirow[t]{4}{*}{ LOL } & L1 & 1.00 & -0.1 & 0.99 & -0.3 \\
\hline & $\mathrm{L} 2$ & 1.01 & 0.2 & 1.01 & 0.3 \\
\hline & L3 & 1.01 & 0.2 & 1.01 & 0.4 \\
\hline & L4 & 1.02 & 0.7 & 1.02 & 1.0 \\
\hline \multirow[t]{4}{*}{ CRE } & $\mathrm{C} 1$ & 0.99 & -0.1 & 1.00 & -0.2 \\
\hline & $\mathrm{C} 2$ & 1.02 & 0.4 & 1.01 & 0.6 \\
\hline & $\mathrm{C} 3$ & 1.01 & 0.6 & 1.02 & 0.9 \\
\hline & $\mathrm{C} 4$ & 0.99 & -0.3 & 0.99 & -0.4 \\
\hline \multirow[t]{4}{*}{ POO } & P1 & 1.02 & 0.5 & 1.01 & 0.7 \\
\hline & $\mathrm{P} 2$ & 1.01 & 0.2 & 1.01 & 0.4 \\
\hline & P3 & 0.99 & -0.2 & 0.99 & -0.4 \\
\hline & $\mathrm{P} 4$ & 1.00 & -0.0 & 1.00 & -0.1 \\
\hline \multirow[t]{4}{*}{$A B S$} & $\mathrm{~A} 1$ & 1.01 & 0.3 & 1.01 & 0.5 \\
\hline & $\mathrm{A} 2$ & 1.05 & 1.5 & 1.05 & 2.2 \\
\hline & A3 & 0.97 & -0.8 & 0.97 & -1.3 \\
\hline & A4 & 0.98 & -0.7 & 0.98 & -0.9 \\
\hline
\end{tabular}




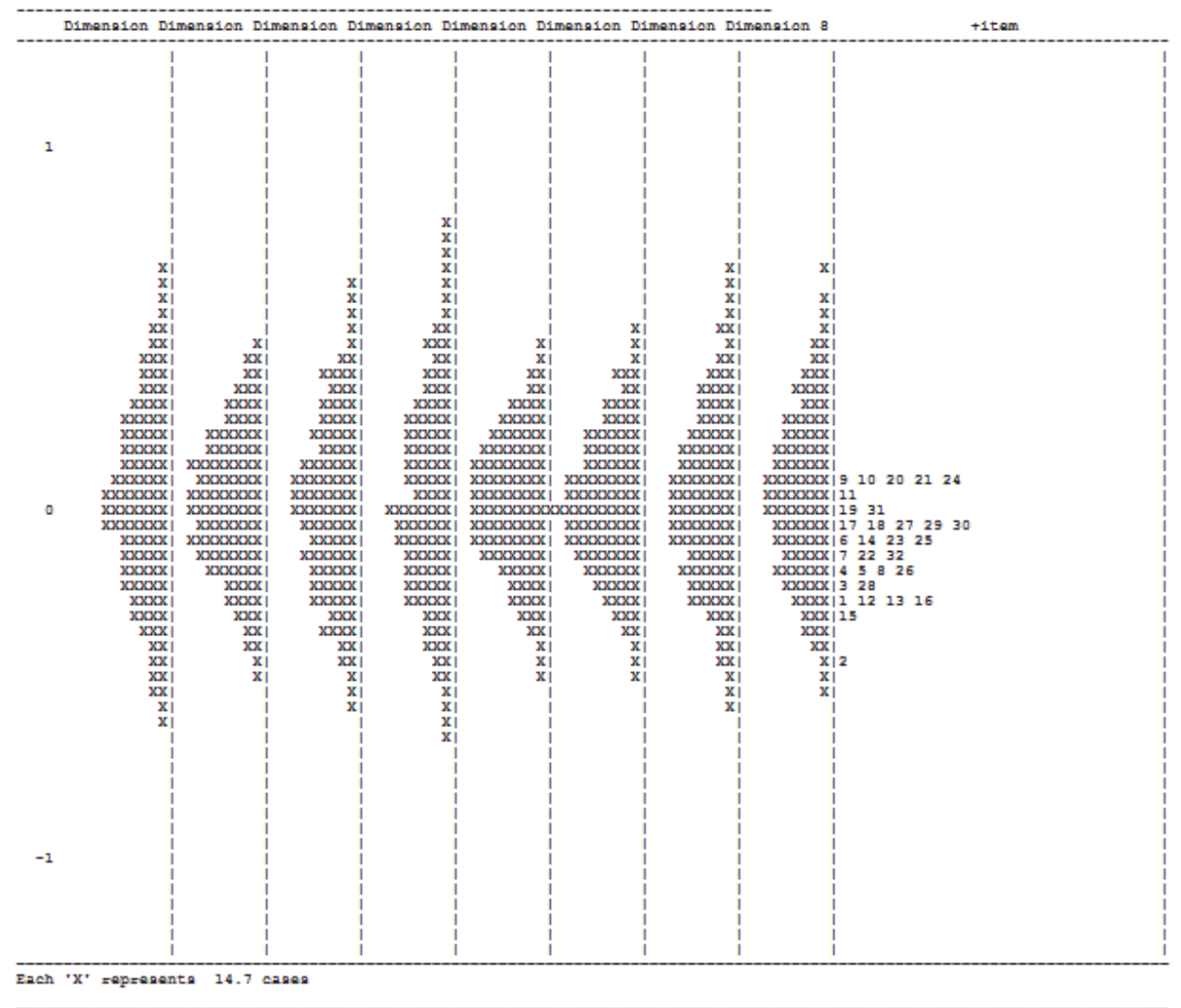

Figure 1: A wright map for the multidimensional SDLmodel

\section{Discussion}

It has been evidenced that the SDL model for the present study exhibits high value of construct validity, as shown by the confirmatory factor analysis and multidimensional item response analysis. It has the construct validity as discussed above.

The analyses for supporting the construct validity of the SDL scale show highly positive results, from the confirmatory factor analysis and the multidimensional item response analysis. These results show that the present scale consisted of eight factors: openness to learning opportunities, self-conception as an effective learner, initiative and independence in learning, informed acceptance of responsibility for one's own learning, love of learning, creativity, a positive orientation to the future, and the ability to use basic study skills and problem-solving skills and the SDLprinciple was synthesised from Rogers's concept of new knowledge introduction (Rogers, 1983) and Cross's concept of SDL (cross, 1981). Awareness, interest, attempts at learning and practice is fit to the empirical data. According to the researchers, the latent structure of SDL is multidimensional and complex. Moreover, the measurement of SDL as a unitary dimension does not yield clear results. As shown by the scale development process in the present research.

The confirmatory factor analysis was then employed so that the researcher could test the relationship between the model and the empirical data (Mclntire \& Miller, 2007). The first topic for discussion is the SDLmodel. This study found that, in the SDLmodel as analysed by analysis factors, when considered item-by-item, two items (6.20\%) did not pass the statistical significance. It is considered that this model was perfectly appropriate (93.80\%) and consistent with overall statistics of the model, which can be considered from statistics of congruence with the empirical data. All statistics were acceptable and reflected congruence between the model and empirical data. The SDLmodel of technical college students was developed from theories by Guglielmino (1977) Rogers (1983) and Cross (1981) consisted of eight factors, namely openness to learning opportunities, self-conception as an effective learner, initiative and independence in learning, informed acceptance of responsibility for one's own learning, love of learning, creativity, a positive orientation to the future, and the ability to use basic study skills and problem-solving skills via confirmatory factor analysis. Analysis of responses to multidimensional tests (confirmatory factor analysis) showed validity according the model with Chi-square test statistics of 418.96 ( $d f=376, p=.062$ ) with no statistical significance. Goodness-of-fit index (GFI) was .98. Adjusted 
goodness-of-fit index (AGFI) was .98. Root mean squared residual (RMR) was .023. Root mean squared error of approximation (RMSEA) was .008. All indexes complied with a consideration of Bollen in 1989 Kelloway in 1998 and Diamantopoulos and Siguaw in 2000, who showed the model synthesised, with congruence with empirical data (Bollen, 1989; Kelloway, 1998; Diamantopoulos \& Siguaw, 2000).

The multidimensionality approach was chosen when it was evident that unidimensionality was not appropriate for measuring self-directed learning; thus the multidimensionality construct validity analyses for the more structurally appropriate model (Wolfe \& Smith, 2007). The SDL model analysed by the multidimensional factors found appropriateness of every item and item fit. Wright et al. (1994) suggest statistics of congruence based on estimation with values from .60 to 1.40. This means that all items were congruent with the SDLmodel under the theory of responses to multidimensional tests (Chianchana, 2009), i.e. students with high SDLcapabilities had a higher chance of answering these items than students with low SDLcapabilities.

\section{Recommendations}

The SDL scale tested in this study will be beneficial for investigations of technical college students' self-directed learning. The scale will help teachers and researchers analyse the strengths and weaknesses of students' self-directed learning, as well as point out to students the importance of learning, technical college should regularly investigate their students' SDL so that the students can develop those factor/dimension continuously. It should be pointed out, however, that the results of the SDL survey be interpreted with caution, as it is a between-item multidimensionality scale. Similarly, the employment of the scale with a different group of students requires both improvement and revision, and the quality of the scale should be examined before actual use so that the results will reflect the specific groups of students. Further research can be conducted on every factor/dimension of the SDL model and in-depth evaluation of SDL can be performed using time-series analysis.

\section{Acknowledgments}

This part of research work is funded by the Office of the Higher Education Commission, and King Mongkut's University of Technology, North Bangkok, Thailand.

\section{References}

Abdollahi, B. (2009). Self-directed Learning in Education and Improvement of Human Resources. Journal for Management of Police Education, 29-47

Adams, R., Wilson, M., \& Wang, W. (1997). The multidimensional random coefficients multinomial logit model. Applied Psychological Measurement, 21, 1-23.

Akaike, H. (1987). Factor analysis and AIC. Psychometrica, 52(3), 317-332.

Allen, D.D., and Wilson, M. (2006). Introducing multidimensional item response modeling in the behavioral sciences. Health Education Research Theory \& Practice, 23, 1-12. Retrieved from http://her.oxfordjournals.org/cgi/ reprint/cyl086v2.

Bollen, K.A. (1989). Structural equations with with latent variables. New York, NY: John Wiley \& Sons, Inc.

Chianchana, C. (2009). Multidimensional analysis. Journal of Education Khon Kaen University, 32(4), 13-22.

Cross, K. P. (1981). Adults as learners: Increasing participation and facilitating Learning. San Francisco: Jossey-Bass.

Diamantopoulos, A., \& Siguaw, J.A. (2000). Introducing LISREL: A Guide for the uninitiated. London: SAGE Publication.

Field, L., 1989. An investigation into the structure, validity and reliability of Guglielmino's self-directed learning readiness scale. Adult Education Quarterly, 39 (3), 125-139.

Field, L. (1991). Guglielmino's self-directed learning readiness scale: should it continue to be used?. Adult Education Quarterly, 41(2), 100-103.

Fisher, M., King, J., \& Tague, G. (2001). Development of a self-directed learning readiness scale for nursing education. Nurse Education Today, $21,516-525$.

Gibbons, M. (2002). The self-directed learning handbook: Challenging adolescent students to excel. San Francisco: Jossey-Bass.

Guglielmino, L.M. (1977). Development of the Self-Directed Learning Readiness Scale.

Unpublished Doctoral Dissertation, University of Georgia. Dissertation Abstracts International, 38 (11a), 6467.

Guglielmino, L. M. (1989). Guglielmino responds to field's investigation. Adult Education Quarterly, 39(4), 235-240.

Guglielmino, L. M., \& Guglielmino, P. J. (2003). Identifying learners who are ready for e-learning and supporting their success. In G. Piskurich (Ed.), Preparing learners for e-learning. San Francisco: Jossey-Bass.

Hair, J.F., Black, W.C., Babin, B.J., Anderson, R.E., \& Tatham, R.L.(2006).Multivariate Data Analysis (6th ed). New Jersey: Pearson Education.

Hair, J.F., Anderson, R.E., Tatham, R.L., \& Black, W.C. (2010). Multivariate data analysis : A global perspective (7th ed). New Jersey: 
Pearson education.

Hoban, J.D., Lawson, S.R., Mazmanian, P.E., Best, A.M., Seibel, H.R., 2005. The selfdirected learning readiness scale: a factor analysis study. Medical Education, 39(4), 370-379.

Kellowey, E. (1998). Using LISREL for structural equation modeling: A researcher's guide. Thousand Oaks: SAGE Publications.

Liu,O.L. Wilson,M., \& Paek, I. (2008). A multidimensional rasch analysis of gender differences in PISA mathematics. Journal of Applied Measurement, 9(1), 18-35.

McIntire, S.A., \& Miller, L.A. (2007). Foundations of psychological testing :A practice approach (2 nd ed.). Thousand Oaks: Sage Publication.

Morizot, J., Ainsworth, A.T., \& Reise, S. (2007) Toward modern psychometrics : Application of item response theory models. In R.W. Robins, R.C. Fraley, and R.F. Krueger (Eds.), Handbook of research methods in personality psychology. (pp. 407-423). New York: Guilford Press.

Office of the Education Council. (2002). The National Education Act 1999 and amendment (vol. 2) 2002. Bangkok: Office of the Education Council.

Reckase, M.D. (1979). Unifactor latent trait models applied to multifactor tests: Results and implications. Journal of Educational Statistics, 4(3), 207-230.

Rogers, C. R. (1983). Freedom to learn for the 80's. Columbus, OH: Merrill.

Williamson, S.N. (2007). Development of a self-rating scale of self-directed learning. Nurse Res. 14(2): 66-83.

Wright, B. D., Linacre, J.M., Gusafson, J.E., \& Martin-Lof, P. (1994). Reasonable mean-square fit values. Rasch Measurement Transactions. Retrieved from http://www.rasch.org/rmt/rmt83b.htm.

Wolfe, E.W., \& Smith, E.V. (2007). Instrument tools and activities for measure validation using rasch models: Part II - Validation activities. Journal of Applied Measurement, 8(2), 204-234.

Yao, L. \& Schwarz, R.D. (2006). A multidimensional partial credit model with associated item and test statistics : An application to mixed-format tests. Applied Psychological Measurement, 30(6), 469-492.

Yen, W.M. \& Fitzpatrick, A.R. (2006). Item response theory. In R.L. Brennan (ed.), Educational Measurement. (4th ed., pp. 111-153). American Council on Education and Praeger Publishers: America. 